\title{
Assessment of MTI Water Temperature Thermal \\ Discharge Retrievals with Ground Truth
}

Taken in the Pilgrim Nuclear Power Station

WSRC-TR-2002-00380

Malcolm M. Pendergast* and Robert J. Kurzeja**

*SMP Enterprises

Martinez. GA

** Savannah River Technology Center

Westinghouse Savannah River Co. 
This document was prepared in conjunction with work accomplished under Contract No. DE-AC09-96SR18500 with the U. S. Department of Energy.

\section{DISCLAIMER}

This report was prepared as an account of work sponsored by an agency of the United States Government. Neither the United States Government nor any agency thereof, nor any of their employees, makes any warranty, express or implied, or assumes any legal liability or responsibility for the accuracy, completeness, or usefulness of any information, apparatus, product or process disclosed, or represents that its use would not infringe privately owned rights. Reference herein to any specific commercial product, process or service by trade name, trademark, manufacturer, or otherwise does not necessarily constitute or imply its endorsement, recommendation, or favoring by the United States Government or any agency thereof. The views and opinions of authors expressed herein do not necessarily state or reflect those of the United States Government or any agency thereof.

This report has been reproduced directly from the best available copy.

Available for sale to the public, in paper, from: U.S. Department of Commerce, National Technical Information Service, 5285 Port Royal Road, Springfield, VA 22161, phone: (800) 553-6847, fax: (703) 605-6900

email: orders@ntis.fedworld.gov

online ordering: http://www.ntis.gov/help/index.asp

Available electronically at http://www.osti.gov/bridge

Available for a processing fee to U.S. Department of Energy and its contractors, in paper, from: U.S. Department of Energy, Office of Scientific and Technical Information, P.O. Box 62, Oak Ridge, TN 37831-0062,

phone: (865)576-8401,

fax: (865)576-5728

email: $\underline{\text { reports@ adonis.osti.gov }}$ 


\section{Table of Contents}

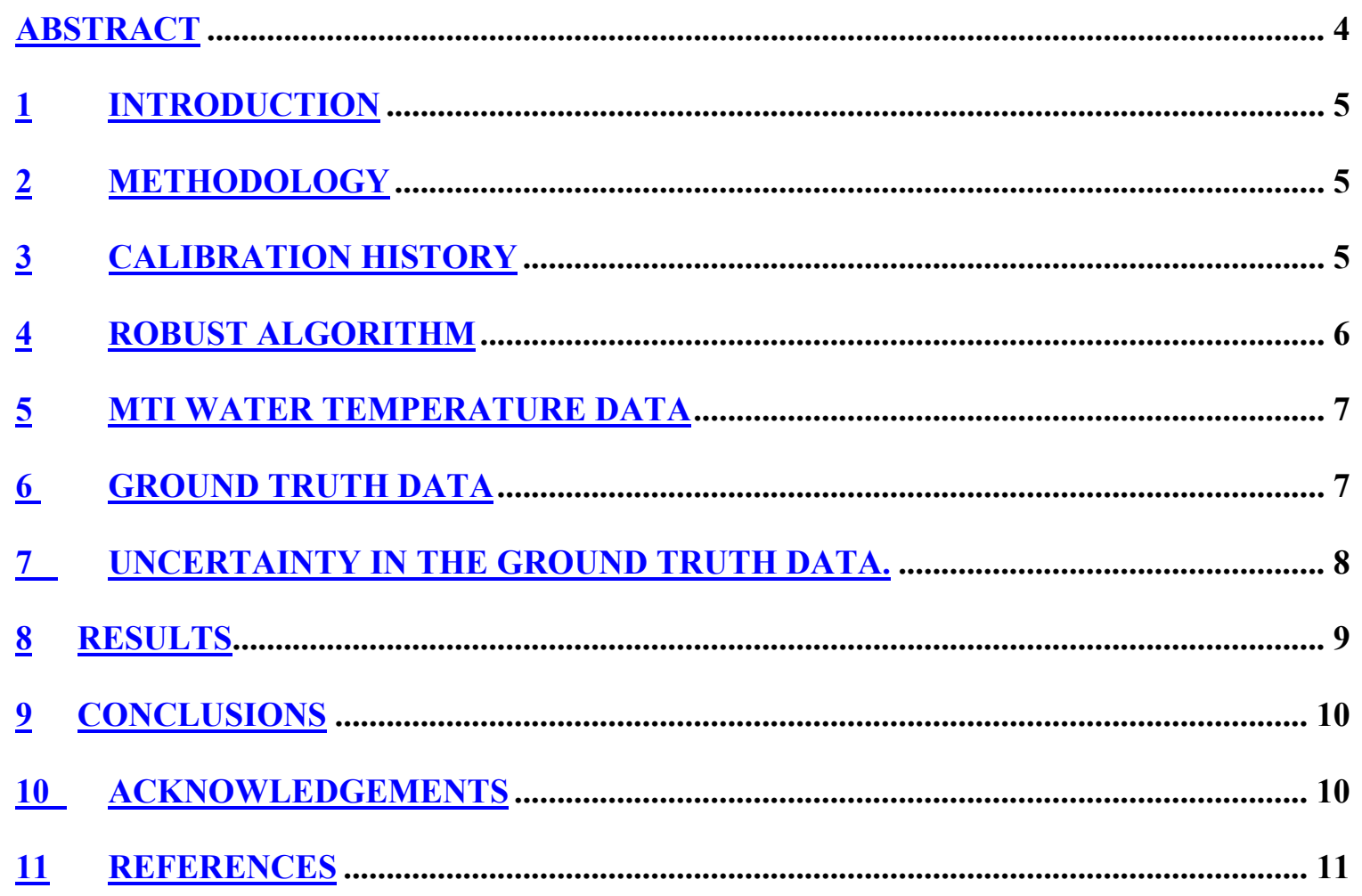




\section{List of Figures.}

FiguRE 1. MTI IMAGE OF PILGRIM SHOWING APPROXIMATE LOCATION OF MONITORING BUOYS A-F. ........ 12 Figure 2. PORTION OF MTI WST-R IMAGE NO. 0101737 COLLECTED 2/03/01 SHOWING THE SCA BOUNDARIES 12

FiguRE 3. PLOT OF WST-R VALUES ALONG THE SCA BORDER ON IMAGE NUMBER 0101737 2/03/01. THE UPPER CURVE IN BLUE IN TAKEN ALONG THE EASTERN MOST PORTION OF THE CENTER SCA AND THE LOWER CURVE IN PINK WAS TAKEN ALONG THE WESTERN-MOST PORTION OF THE EASTERN SCA.......... 13

FIGURE 4. VARIATION IN SCA BIAS FOR ALL MTI IMAGES USED IN THE STUDY ( PINK SQUARES) AND A MEASURE OF ATMOSPHERIC WATER VAPOR CONTENT PROPORTIONAL TO THE DIFFERENCE IN TOP-OFATMOSPHERE BRIGHTNESS TEMPERATURE BETWEEN MTI BAND N AND MTI BAND K (BLUE DIAMONDS).

Figure 5. Plot of WST-R and AdJusted TidBit Temperatures for Pilgrim BuOY Location "A". 14 Figure 6. Plot OF WST-R AND AdJUSTED TidBit TEMPERATURES FOR PILgRIM BUOY LOCATION "B".. 14 Figure 7. Plot OF WST-R AND AdJUSTED TidBit TEMPERATURES FOR PILGRIM BUOY LOCATION "C". 15 Figure 8. Plot OF WST-R AND AdJUSTED TidBit TemPeratures For PILGRIM BUOY LOCATION "D". 15 Figure 9. Plot OF WST-R AND ADJUSTED TIDBIT TEMPERATURES FOR PILGRIM BUOY LOCATION "E".. 16 Figure 10. Plot OF WST-R AND AdJUSTED TidBit TEMPERATURES FOR PILGRIM BUOY LOCATION "F". ……n.

FIGURE 11. WATER TEMPERATURE RETRIEVAL ERRORS FOR ALL OPEN BUOYS......................................... 17

FigURE 12. WATER TEMPERATURE RETRIEVALS FOR COMBINED OPEN BUOYS C, D AND E........................ 17

\section{List of Tables.}

TABLE 1. COEFFICIENTS FOR CALCULATING WST FROM TOP-OF-ATMOSPHERE BRIGHTNESS TEMPERATURES OF MTI THERMAL BANDS FOR ZENITH-TO-MTI ANGLES RANGING FROM 0 TO 40 DEGREES. (PROVIDED

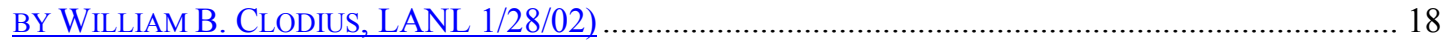

TABLE 2. SPATIAL ERRORS OF WST AT PILGRIM BUOY LOCATIONS FOR ALL IMAGE TIMES....................... 19

TABLE 3. ERRORS ASSOCIATED WITH ADJUSTING THE TIDBIT TEMPERATURES AT PILGRIM BUOY

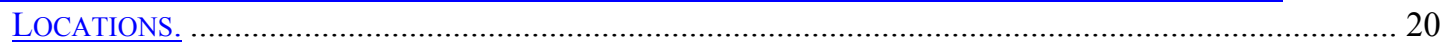

TABLE 4. LISTING OF ALL DATA USED IN THE WST-R EVALUATION FOR PILGRIM........................................ 21

TABLE 5. LISTING AND DEFINITINS OF ALL COLUMN HEADINGS ON TABLE 4 ................................................ 23

TABLE 6. SUMMARY OF BIAS AND RMS ERROR FOR WST-R AND TIDBIT COMPARISONS. .......................... 24 


\begin{abstract}
Surface water temperatures calculated from Multispectral Thermal Imager (MTI) brightness temperatures and the robust retrieval algorithm, developed by the Los Alamos National Laboratory (LANL), are compared with ground truth measurements at a mid-latitude cold-water site along the Atlantic coast near Plymouth, MA.

In contrast to the relative uniformity of the sea-surface temperature in the open ocean the water temperature near Pilgrim exhibits strong spatial gradients and temporal variability. This made it critical that all images be accurately registered in order to extract temperature values at the six buoy locations. Sixteen images during a one-year period from August 2000 to July 2001 were selected for the study.

The RMS error of Pilgrim water temperature is about 3.5 C for the 4 buoys located in open water. The RMS error of the combined temperatures from 3 of the open-water buoys is $2.8 \mathrm{C}$. The RMS error includes errors in the ground truth. The magnitude of this error is estimated to range between 0.8 and $2.3 \mathrm{C}$. The two main components of this error are warm-layer effect and spatial variability. The actual error in the MTI retrievals for Pilgrim daytime conditions is estimated to be between 2.7 and 3.4 $\mathrm{C}$ for individual buoys and between 1.7 and $2.7 \mathrm{C}$ for the combined openwater buoys.
\end{abstract}




\section{$1 \quad$ Introduction}

This report evaluates MTI-derived surface water temperature near the Pilgrim Nuclear Power Station thermal discharge. This location represents a cold-water target to supplement the evaluation conducted in the tropical western Pacific at Nauru (Kurzeja and Pendergast, 2002). For the remainder of this report this document will be referred to as the Nauru study. The MTI seasurface temperatures were determined by the Los Alamos National Laboratory, LANL, based on the 'robust retrieval' (Tornow and Borel, 1994 and Tornow et al, 1994).

\section{$2 \quad$ Methodology}

The Pilgrim study evaluates water temperature retrievals at six locations located near the hot water discharge and the cold-water intake. In contrast to the relative uniformity of the seasurface temperature at Nauru, the water temperature near Pilgrim exhibits strong spatial gradients and temporal variability. This made it critical that all images be accurately registered in order to extract temperature values at the six buoy locations. Once registered, water temperatures were extracted from the MTI Water Surface Temperature, WST, images for 9 pixels centered over each buoy location. These temperatures were adjusted for bias and then compared to the representative buoy temperatures.

\section{Calibration History}

The calibration history of the MTI was discussed by Atkins et al. (2001). They asserted that the $1 \%$ design accuracy in the IR bands had probably been achieved after launch but noted variability in the top-of-atmosphere brightness temperature, TOAB, between the three sensor chip arrays, SCA's, of up to $\sim 0.5 \mathrm{C}$ for uniform sea-water targets in bands $\mathrm{K}$ and $\mathrm{L}$. They argued that this variability was probably caused by uncertainty in the individual SCA filter functions, especially at short wavelengths, and was not due to radiometric differences. Thus, the TOAB of the SCA's would be expected to vary from scene to scene and Atkins et al. estimated this effect to be $\sim 0.5 \mathrm{C}$ for band $\mathrm{L}$.

On Oct 31, 2001 the MTI Telescope and Calibration Control Unit (TCAL) experienced a power failure. This shut down the optical assembly operational heaters (with a $\sim 28 \mathrm{C}$ decrease in temperature), and caused the loss of the secondary mirror focus adjustment, door assembly, black body panel, visible panel, and quick calibration wheel assembly. After this failure, the calibration sequence was replaced by two deep-space looks. Periodic moon looks and ground calibration are being used to monitor changes in performance.

The quality of the MTI radiances, particularly in the IR, grew worse after the Oct 31 TCAL failure and greater offsets between the SCA's and linear variations in radiance across individual SCA's were observed. These have been attributed to thermally-induced mechanical shifts in the optics. This problem has been corrected by viewing targets with the satellite rotated by 90 degrees, i.e., viewing the same area with all pixels in each SCA. Differences between the SCA's have been corrected by normalizing SCA's 2 and 3 to the high end of SCA2, which also 
improved consistency with SCA1. Variations in radiance within SCA's have been corrected with 90 degree looks at uniform ocean targets.

The loss of the black body panels also precludes non-linear corrections in the radiance values and calibration of individual pixels. These corrections were maintained as before the TCAL failure.

In summary, Atkins et al. (2001) estimated a degradation in the inferred surface temperatures of 0.5-3.0C in brightness temperatures after the TCAL failure, with more specific estimates reserved for a later date.

\section{Robust Algorithm}

The MTI product evaluated in this report is called the Robust Water Surface Temperature, WST$\mathrm{R}$, referred to as WST in this report. This product was supplied to SRTC by the Los Alamos National Laboratory, and consists of a single band image with a resolution of $20 \mathrm{~m}$. The values are floating point and in degrees Kelvin. The WST algorithm utilizes several sets of coefficients that are applied to TOAB of MTI bands J, K, L, M and N as a function of the Zenith-to-MIT angle. TOAB values can be generated internally within the algorithm or obtained as one of the MTI products and the angle, Zenith2MTI, is obtained from the MTI image header text file. Table 1 shows WST coefficients for daytime and nighttime developed by Tornow and Borel (1994) which are based upon LOWTRAN simulations for 380 different atmospheres. Although both nadir and backward looks can be used to calculate robust temperatures, only the nadir look has been used in this study.

LANL determines coefficients for a specific Zenith-to-MTI angle by interpolation from adjacent angles. SRTC has developed regression equations to provide coefficients as a function of Zenithto-MTI angle for ease of incorporating the WST computation within an Excel spreadsheet and/or an ENVI band math expression. Equation (1) and (2) give TDAY ${ }_{\text {WST }}$ and TNITE WST $_{\text {for daytime }}$ and nighttime respectively, where $\mathrm{A}$ is the zenith-to-MTI angle and TOABi are brightness temperatures for MTI band "i". All temperatures are in degrees Kelvin.

$$
\begin{aligned}
& \mathrm{TDAY}_{\mathrm{WST}}=\left(0.003547 * \mathrm{~A}^{2}-0.03283 * \mathrm{~A}+5.8330\right)+\left(0.000027 * \mathrm{~A}^{2}\right. \\
& +0.004071 * \mathrm{~A}+0.32116) * \mathrm{TOAB}_{\mathrm{K}}+ \\
& \left(-0.000237 * \mathrm{~A}^{2}-0.011829 * \mathrm{~A}-3.11275\right) * \mathrm{TOAB}_{\mathrm{L}}+\left(0.000072 * \mathrm{~A}^{2}+0.005715 * \mathrm{~A}+1.8901\right) \\
& \text { TOAB }_{\mathrm{M}}+\left(0.00012 * \mathrm{~A}^{2}-0.002243 * \mathrm{~A}+1.86854\right) * \mathrm{TOAB}_{\mathrm{N}} \\
& \\
& \text { TNITE }_{\text {WST }}=\left(0.0005894 * \mathrm{~A}^{2}-0.07613 * \mathrm{~A}+15.0502\right)+\left(0.000124 * \mathrm{~A}^{2}+\right. \\
& 0.001082 * \mathrm{~A}+1.9640) * \mathrm{TOAB}_{\mathrm{J}}+\left(0.000042 * \mathrm{~A}^{2}+0.000679 * \mathrm{~A}+0.64521\right) * \mathrm{TOAB}_{\mathrm{K}} \\
& +\left(0.000054 * \mathrm{~A}^{2}-0.002085 * \mathrm{~A}-1.51868\right) * \mathrm{TOAB}_{\mathrm{L}}+ \\
& \left(-0.000551 * \mathrm{~A}^{2}+0.003844 * \mathrm{~A}-3.55281\right) * \mathrm{TOAB}_{\mathrm{M}}+\left(0.000306^{*} \mathrm{~A}^{2}-\right. \\
& 0.003158 * \mathrm{~A}+3.38763) * \mathrm{TOAB}_{\mathrm{N}}
\end{aligned}
$$

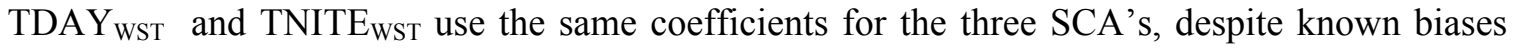
between the SCA's. Thus, one result from this study is to document the magnitude of these biases. 


\section{$5 \quad$ MTI Water Temperature Data}

The Pilgrim study evaluates WST-R at six locations near the hot water discharge and the cold water intake as shown in Figure 1. See details of ground truth data in the Pilgrim Ground Truth Report (Parker and Garrett, 2002). In contrast to the relative uniformity of the sea-surface temperature at Nauru the water temperature near Pilgrim exhibits strong spatial gradients and temporal variability. This made it critical that all images be accurately registered in order to extract temperature values at the six buoy locations. All daytime images were geo-registered by Paul Pope of LANL using the latest LANL algorithm (Paul Pope, LANL, personal communication). Nighttime images were registered to a United States Geological Survey map with $1 \mathrm{~m}$ resolution using the Environment for Visualizing Images, ENVI, software package (Research Systems Inc., Boulder CO, envi@ResearchSystems.com).

The Nauru study showed differences among the SCAs. The center SCA was found to be biased high by about $1 \mathrm{C}$ over adjacent SCA's. This bias is clearly visible in all WST-R images. Figure 2 shows a portion of the WST-R image number 0101737 collected on 2/03/02, note the boundary of the center and eastern SCA. Figure 3 shows a plot of WST-R from the two SCA's along a portion of this boundary indicating a bias of $0.78 \mathrm{C}$.

Figure 4 shows a plot of the SCA Bias for all images used in this study. Note the magnitude of the SCA Bias seems to be steadily decreasing from a high of $1.7 \mathrm{C}$ on $8 / 22 / 00$ to a minimum of $0.2 \mathrm{C}$ on $7 / 25 / 01$. When the Bias data are fitted to a $2 \mathrm{nd}$ order polynomial the resulting curve shows almost a straight line. This linear decrease in bias may reflect changes in weather conditions or may reflect a gradual improvement in the LANL calibration procedures. A simple way to determine the relative amount of atmospheric water vapor in each image is to calculate the difference in TOAB between MTI band N and MTI band K. Since band K is near a water absorption band, the TOAB will decrease with increasing water vapor. The TOAB for band $\mathrm{N}$ will not be a function of water vapor. In this way low values of the difference in brightness temperatures corresponds to dry conditions and high values correspond to moist conditions. When the moisture data are fitted to a 2 nd order polynomial the resulting curve indicates the expected seasonal variation in water vapor with lowest values occurring in winter and highest values in summer. Thus the decrease in SCA bias throughout the period of study does not seem to be correlated with weather conditions and we must conclude the improvement is due to improved calibration by LANL.

WST-R values were collected from each geo-registered mage from a 3 by 3 array of pixels centered on each buoy position and median value selected to compare with the ground truth data. When buoy positions were within the center SCA the WST-R values were adjusted by subtracting the SCA bias.

\section{$6 \quad$ Ground Truth Data}

The direct measurement of the water surface temperature is difficult and requires infrared radiometers because the surface skin layer is very thin $(<<1 \mathrm{~mm})$ and is cooler than the deeper 'bulk' water. For the Pilgrim study all bulk water temperature were measured at a depth of 30 $\mathrm{cm}$. It is easier to accurately measure the deeper bulk water temperature but this temperature must be adjusted to account both for the cool skin and for any temperature gradient between the bulk water sensor and the near-surface temperature (warm-layer effect). 
A self-contained temperature data logger, called a TidBit, manufactured by Onset Computer Corporation was selected for the study because it is accurate, programmable, inexpensive, and easy to operate. TidBit programming and data downloading is accomplished with proprietary software and a personal computer.

Onset's specified accuracy for the Tidbits is $0.20 \mathrm{C}$, with a resolution of $0.16 \mathrm{C}$. The accuracy can be reduced to $0.10 \mathrm{C}$ with laboratory calibration but this accuracy is only realized as a mean of many data points. The response time of the Tidbit is $\sim 3$ minutes, which requires at least 10 minutes time in the water to converge to within $0.10 \mathrm{C}$ of the water temperature.

As a result of solar heating the near surface temperature is warmer than the water below. This effect has been examined by Fairall et al (1996) showing that the warm-layer effect, $\Delta \mathrm{T}_{\mathrm{wl}}$, can be modeled in terms of a layer depth, temperature difference between the near-surface bulk temperature and the deep-water temperature and wind speed. Fairall's results were interpolated to a depth of $30 \mathrm{~cm}$ and fitted with the expression,

where $u$ is wind speed in $\mathrm{m} / \mathrm{sec}$.

$$
\Delta \mathrm{T}_{\mathrm{wl}}=+7.92 \mathrm{e}^{-0.839 \mathrm{u}},
$$

The skin-temperature effect, $\Delta \mathrm{T}_{\mathrm{st}}$, is a complicated function of heat exchange at the sea surface. In this report we have adapted model results of Fairall et al. (1996), who found skin temperature depressions ranging between of 0.2 and $0.4 \mathrm{C}$ during cloud-free days depending upon wind speed. For this report we have used the expression,

$$
\Delta \mathrm{T}_{\text {st }}=-0.546 \mathrm{e}^{-0.069 \mathrm{u}} .
$$

The adjusted Tidbit temperature, $\mathrm{T}_{\mathrm{adj}}$, is given by,

$$
\mathrm{T}_{\mathrm{adj}}=\mathrm{T}_{30}+\Delta \mathrm{T}_{\mathrm{wl}}-\Delta \mathrm{T}_{\mathrm{st}},
$$

Where $\mathrm{T}_{30}$ is the Tidbit temperature at a depth of $30 \mathrm{~cm}$.

\section{$7 \quad$ Uncertainty in the Ground Truth Data.}

To better interpret the relationship between WST-R and TidBit observations it was necessary to examine the uncertainties associated with the adjustments to the TidBit temperatures. The various components are: sensor accuracy, skin-temperature effect, warm-layer effect and spatial variability.

Warm layer and cool skin uncertainties are based upon discussions provided in the Nauru report interpolated to a depth of $30 \mathrm{~cm}$. The estimates for spatial variability was made using the WST-R image data. It is assumed that the spatial errors are equal to the standard deviation of the nine WST-R values surrounding each buoy location.

Table 2 shows spatial errors for each image and each buoy location with the averages shown at the bottom of each column. Spatial errors for buoy locations A and F are much larger than other buoy locations. The reason for these large spatial errors is that these two locations are located within one or two pixels of land features. The WST-R values are contaminated with "non-water pixels". Buoy locations B through D are farther from shore and the influences from non-water pixels is much reduced. 
Table 3 shows the summary of all components of the error analysis for the near-shore buoys ( A and F) and the open-water buoys (B, C, D andE). Note the largest errors are associated with the warm-layer effect and the spatial variation. These errors will be discussed in the next section on results.

\section{$8 \quad$ Results}

Table 4 contains all data used in the Pilgrim WST-R evaluation and Table 5 provides a description of all column headings and definitions. Figures 5-10 show plots of adjusted TidBit temperatures with the corresponding WST and SCA adjusted WST values for each of the 6 Pilgrim buoy locations. Each plot shows the line of perfect fit in black and least squares fit for the WST values (blue diamonds) and the SCA adjusted WST values in (pink squares). The bias and RMS error of the least-squares fit are displayed in the upper left corner of the plots. The values for the bias and RMS error from Figure 5-10 are summarized in Table 6 along with the bias and RMS errors resulting from the comparison of unadjusted TidBit temperatures and the WST-R data.

Figure 11 shows a plot of water temperature retrieval errors (Adjusted MTI - Adjusted TidBit) for the four open-water buoys for all image times. Most of time the retrieval errors are correlated with one another. The exception is for Buoy location $\mathrm{C}$ for which the retrieval errors do not seem to be correlated with the other buoys. This effect is most pronounced during the first half of the study. The correlation coefficients are listed in the upper left had corner of Figure 11 showing a range of values from 0.52 between $\mathrm{D}$ and $\mathrm{C}$ to 0.94 between $\mathrm{B}$ and $\mathrm{E}$.

Table 6 shows for buoy locations B, C, D and E the lowest bias occurs for the adjusted data and the highest bias occurs for the unadjusted data. The average bias for the unadjusted data is $1.98 \mathrm{C}$ and the average bias for the adjusted data is $0.45 \mathrm{C}$. The corresponding RMS errors for these buoy locations remain fairly constant with an average RMS error for unadjusted data of $3.52 \mathrm{C}$ and the average RMS error for the adjusted data is $3.48 \mathrm{C}$.

Buoy location A shows the highest bias, $6.55 \mathrm{C}$ for the un adjusted data and 5.07 $\mathrm{C}$ for the adjusted data, of all buoy locations although Figure 5 shows the bias is significantly lower for those images when the WST-R values are less than $10 \mathrm{C}$. The results from the TidBit error analysis, particularly the large contribution attributed to spatial variability, only explains a fraction of the bias. The remaining contribution to the bias is probably the result of the nearshore pixels being significantly warmer than the pixels at buoy location A.

Buoy location $\mathrm{F}$ shows the highest RMS error with values around $13 \mathrm{C}$ although the bias varies from $1.44 \mathrm{C}$ for the unadjusted data to $-0.05 \mathrm{C}$ for the adjusted data. This large scatter is probably caused by the location of buoy $\mathrm{F}$ in a narrow canal with roads and buildings in close vicinity with surface emmisivity much different from that of water.

In order to minimize the effect of the spatial variation of TidBit temperatures in the discharge plume, the three buoys, $\mathrm{C}, \mathrm{D}$ and $\mathrm{E}$ were combined to produce a more robust temperature measurement to compare with the MTI retrievals. Figure 12 shows a plot of the resulting average values. Note the bias is $0.72 \mathrm{C}$ and the RMS error is $2.83 \mathrm{C}$. This is significantly less than RMS error from the individual buoy positions of $3.52 \mathrm{C}$. 


\section{Conclusions}

The RMS error of Pilgrim water temperature is $3.52 \mathrm{C}$ for the 4 buoys located in open water. The RMS error of the combined temperatures from 3 of the open-water buoys is $2.83 \mathrm{C}$. The RMS error includes errors in the ground truth which are estimated to range between 0.77 and 2.25 C. The two main components of this error are warm-layer effect and spatial variability. The actual error in the MTI retrievals for Pilgrim daytime conditions is between 2.68 and $3.41 \mathrm{C}$ for individual buoys but range between 1.72 and $2.72 \mathrm{C}$ for the combined open-water buoys.

The Nauru study indicted an apparent improvement of the MTI calibration over the period June 2000 to September 2001. This corresponds to the observed decrease in the SCA bias observed in this study.

The retrieval error was not dependent on the water vapor column amount although some reduction in the RMS error was observed for those images for which the MTI temperature was less than $10 \mathrm{C}$.

The results of this study confirms the advantages of averaging and indicate that even when RMS errors are large for an individual image, the ensemble average values of MTI derived water temperatures agree rather well with ground truth.

\section{Acknowledgements}

The author wishes to thank Kim Starkovitch and Kim Pollock of LANL for their patience in providing processing of all MTI images and to Paul Pope for his diligence in working out problems with the registration of the MTI images. 


\section{References}

Atkins, W., S. Bender, W. Christensen, C. Little E. Riddle, 2001. The Multispectral Thermal Imager Calibration. Presented at the MultiSpectral Thermal Imager Symposium, Sandia National Laboratory, March 12-13, 2001.

Fairall, C. W., E.F. Bradley, J.S. Godfrey, G. A. Wick, J.B. Edson, and G. S. Young, 1996. Coolskin and warm-layer effects on sea surface temperature. J. Geophys. Res, 101, 1295-1308.

Kurzeja, R. J. and M. M. Pendergast, 2002. Comparison of MTI and Ground Truth Sea Surface Temperatures at Nauru. Westinghouse Savannah River Company, WSRC-TR-2002-00294.

Parker, M. J. and A. J. Garrett, 2002. Final MTI Data Report: Pilgrim Nuclear Station.. Westinghouse Savannah River Company, WSRC-TR-2002-00373.

Tornow,C. and C. C. Borel, 1994. Multi-angular multi-spectral night-time water temperature retrieval. MTI Technical Report MTI-94-001.

Tornow, C. C.C. Borel, and B. J. Powers, 1994. Robust water temperature retrieval using multispectral and multi angular IR measuremnets, Proc. IGARSS '94, 441-443, 1994. 


\section{Figures.}

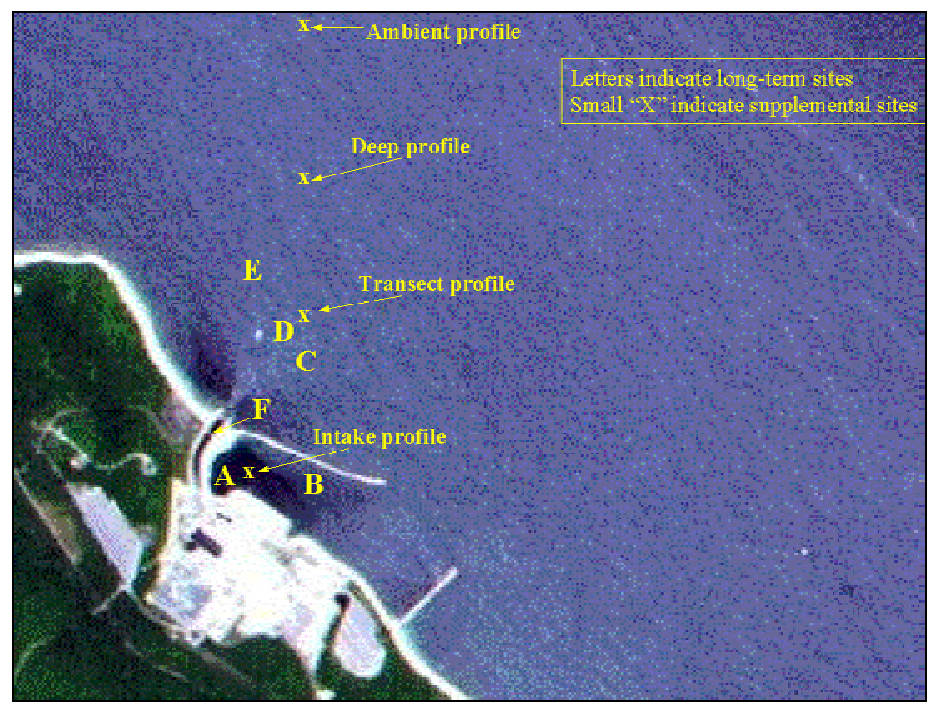

Figure 1. MTI image of Pilgrim showing approximate location of monitoring buoys A-F.

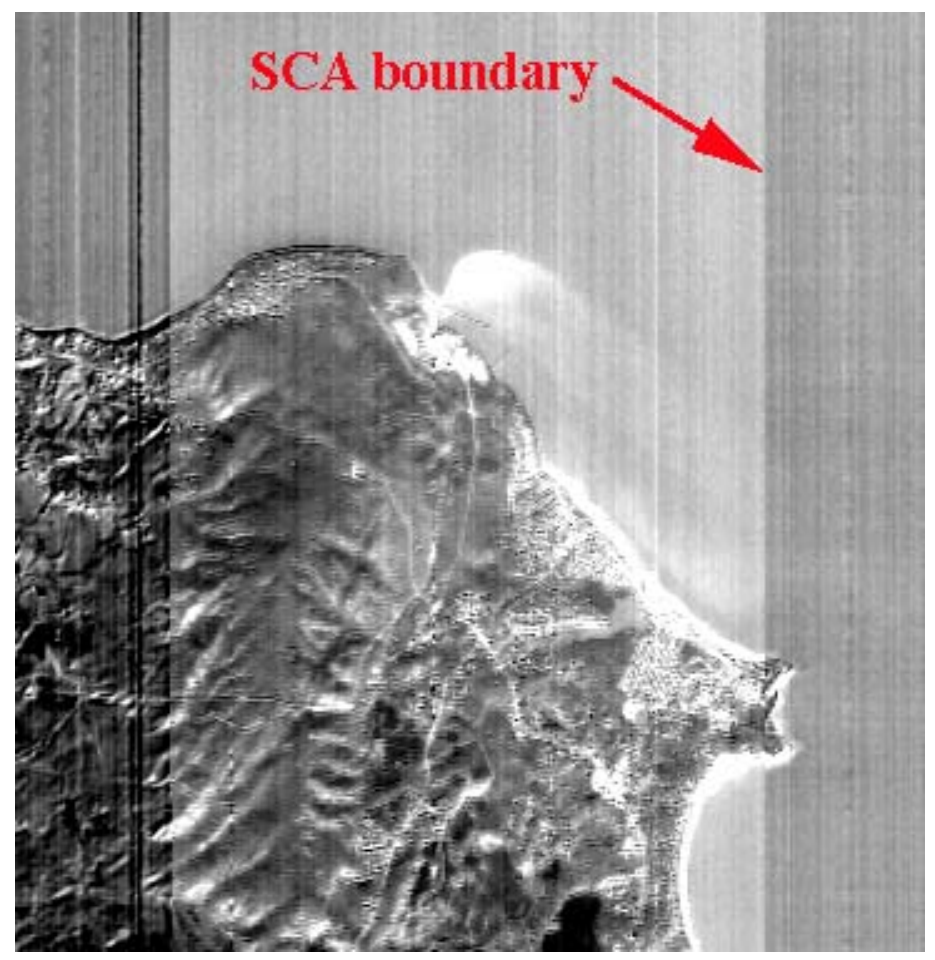

Figure 2. Portion of MTI WST-R Image No. 0101737 collected 2/03/01 showing the SCA Boundaries. 
WSRC-TR-2002-00380

Water Temperature along SCA Boundary Image Number 0101737 2/03/01

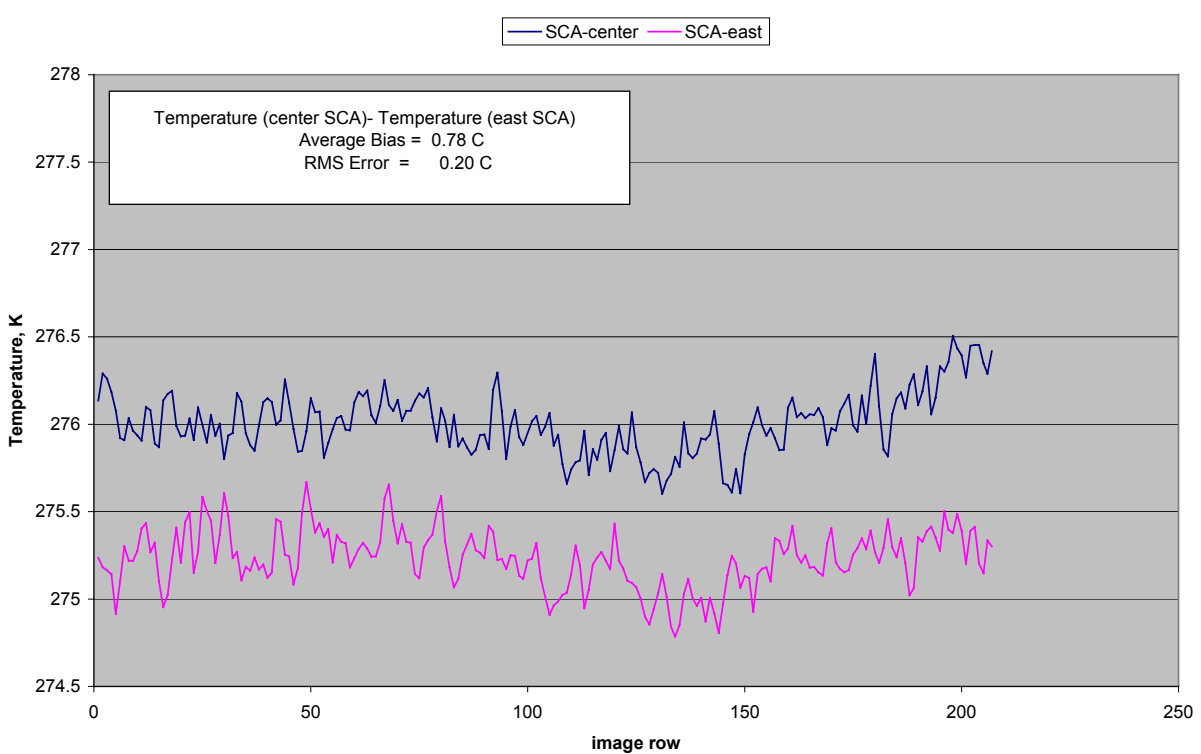

1

Figure 3. Plot of WST-R values along the SCA border on image number 0101737 2/03/01. The upper curve in blue in taken along the eastern most portion of the center SCA and the lower curve in pink was taken along the western-most portion of the eastern SCA.

Variation in SCA Bias as Function of Date and Difference in Top-of-Atmosphere Brightness

Temperature between MTI band $\mathrm{N}$ and $\mathrm{MTI}$ band $\mathrm{K}$

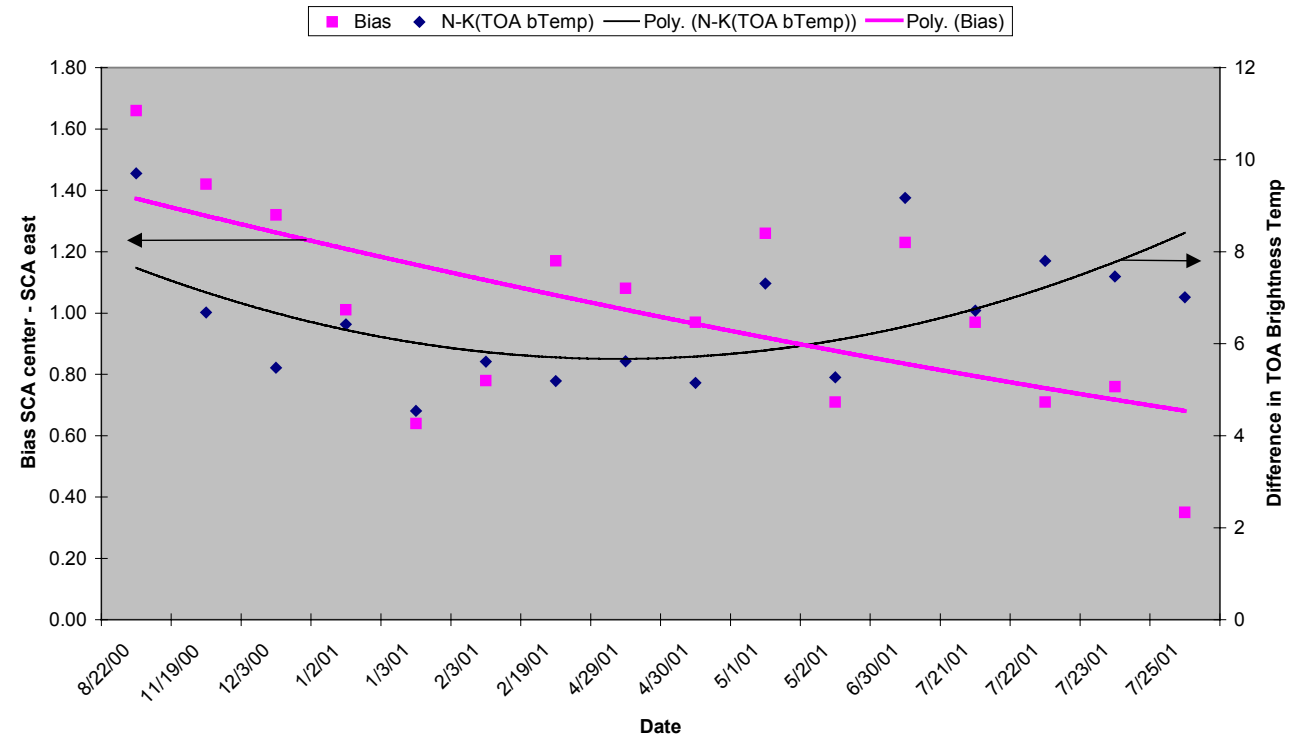

Figure 4. Variation in SCA Bias for all MTI images used in the study ( pink squares) and a measure of atmospheric water vapor content proportional to the difference in Top-of-Atmosphere brightness temperature between MTI band N and MTI band K (blue diamonds). 


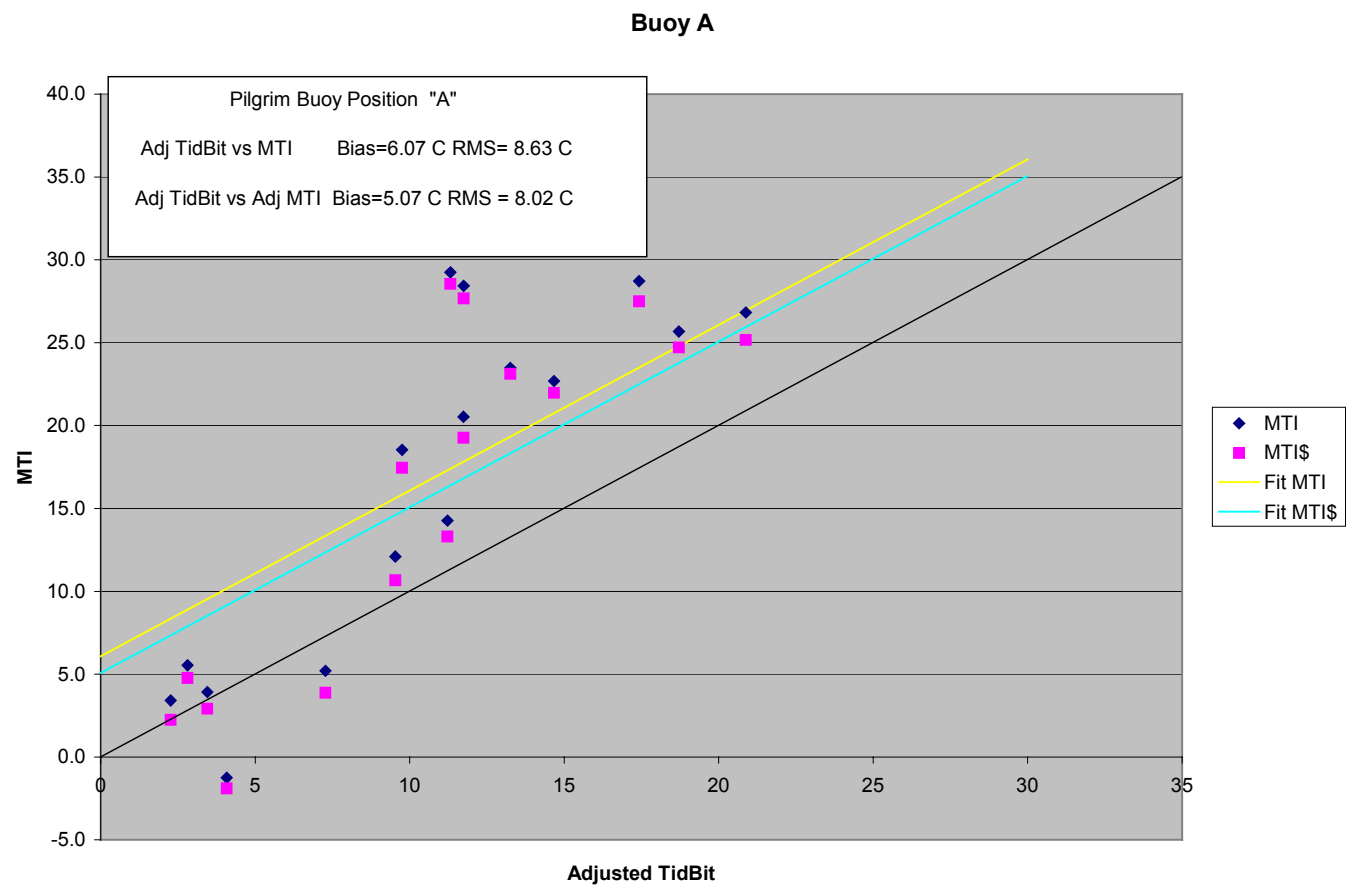

Figure 5. Plot of WST-R and Adjusted TidBit Temperatures for Pilgrim Buoy Location "A".

Buoy B

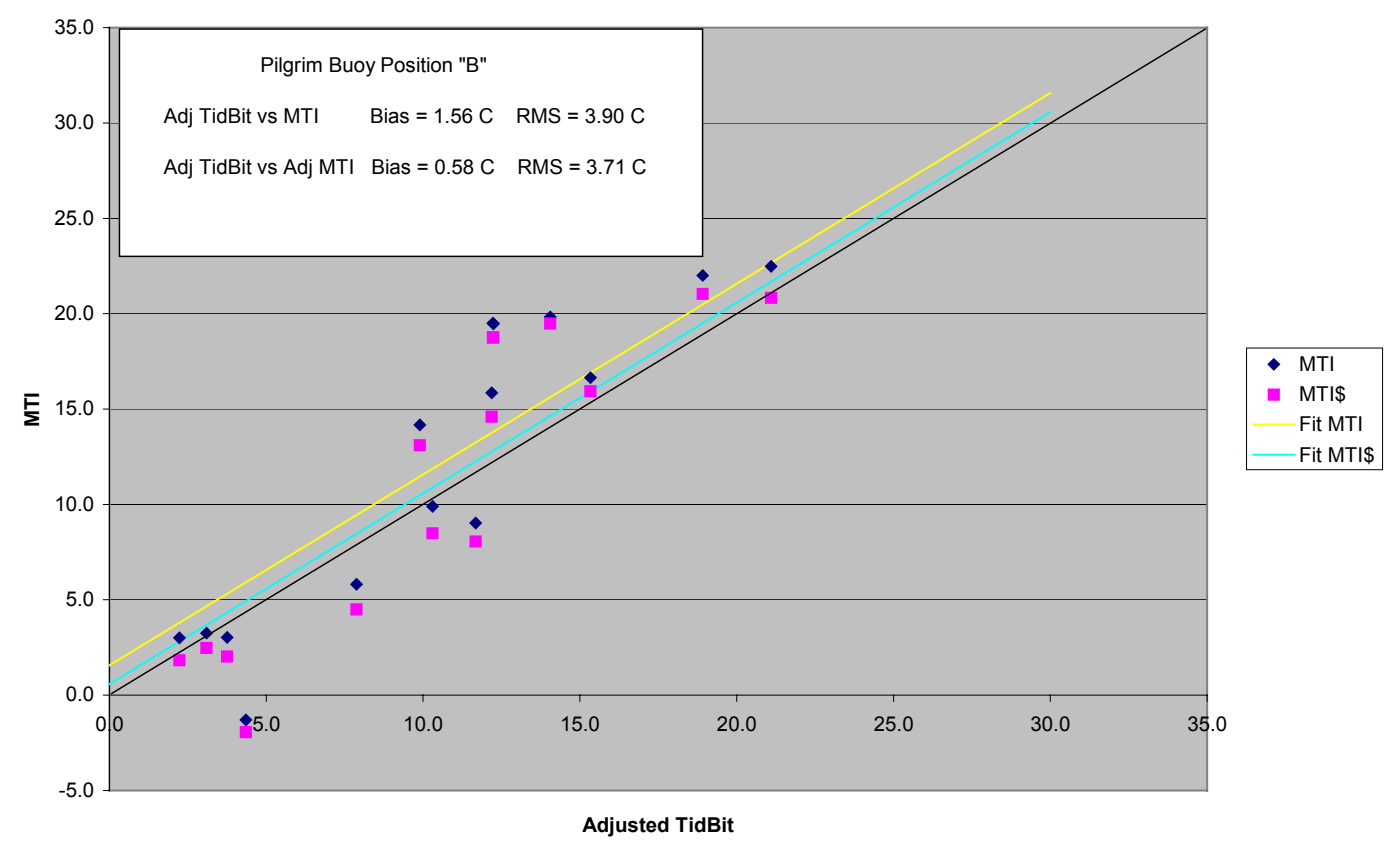

Figure 6. Plot of WST-R and Adjusted TidBit Temperatures for Pilgrim Buoy Location "B". 


\section{Buoy C}

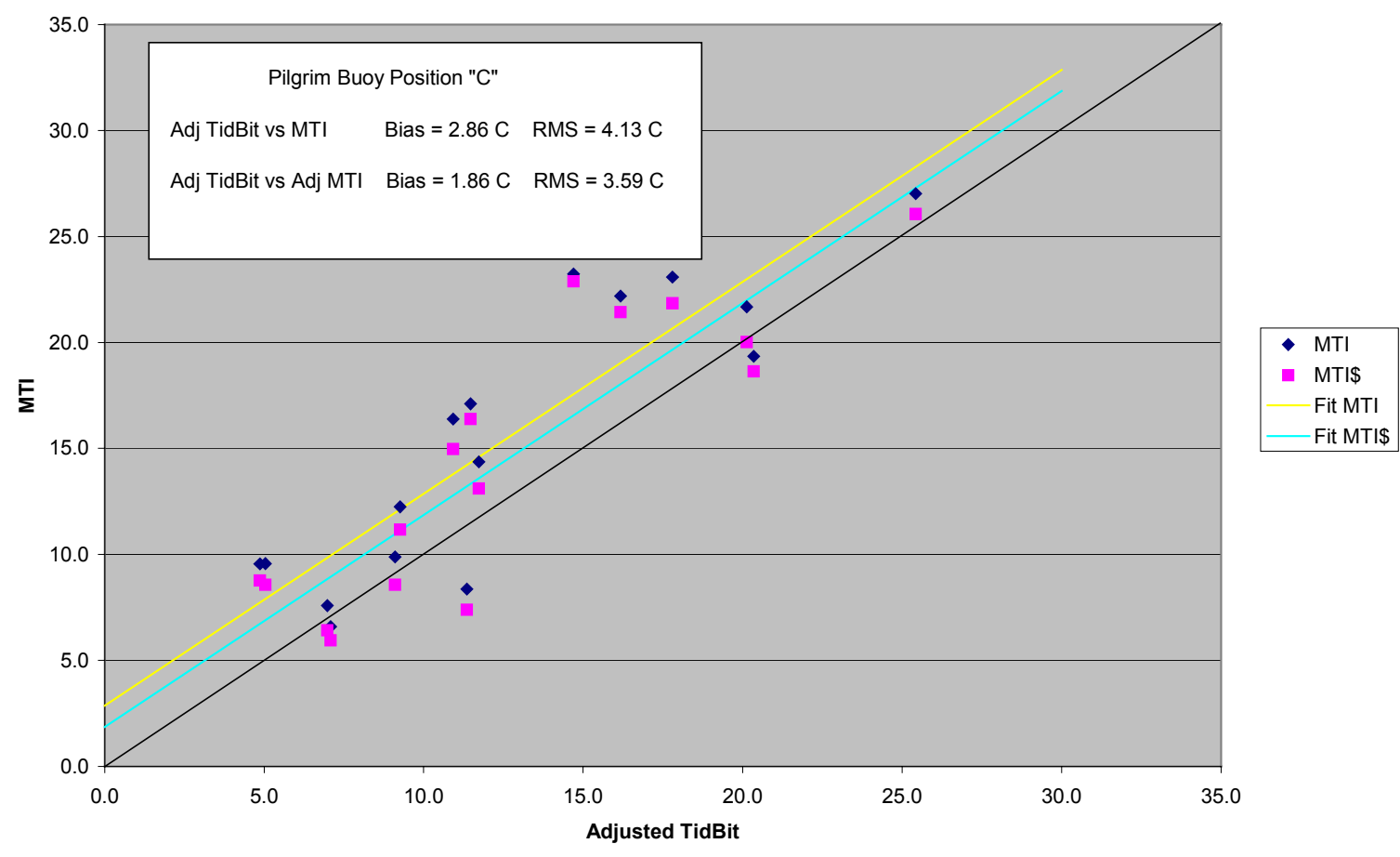

Figure 7. Plot of WST-R and Adjusted TidBit Temperatures for Pilgrim Buoy Location "C".

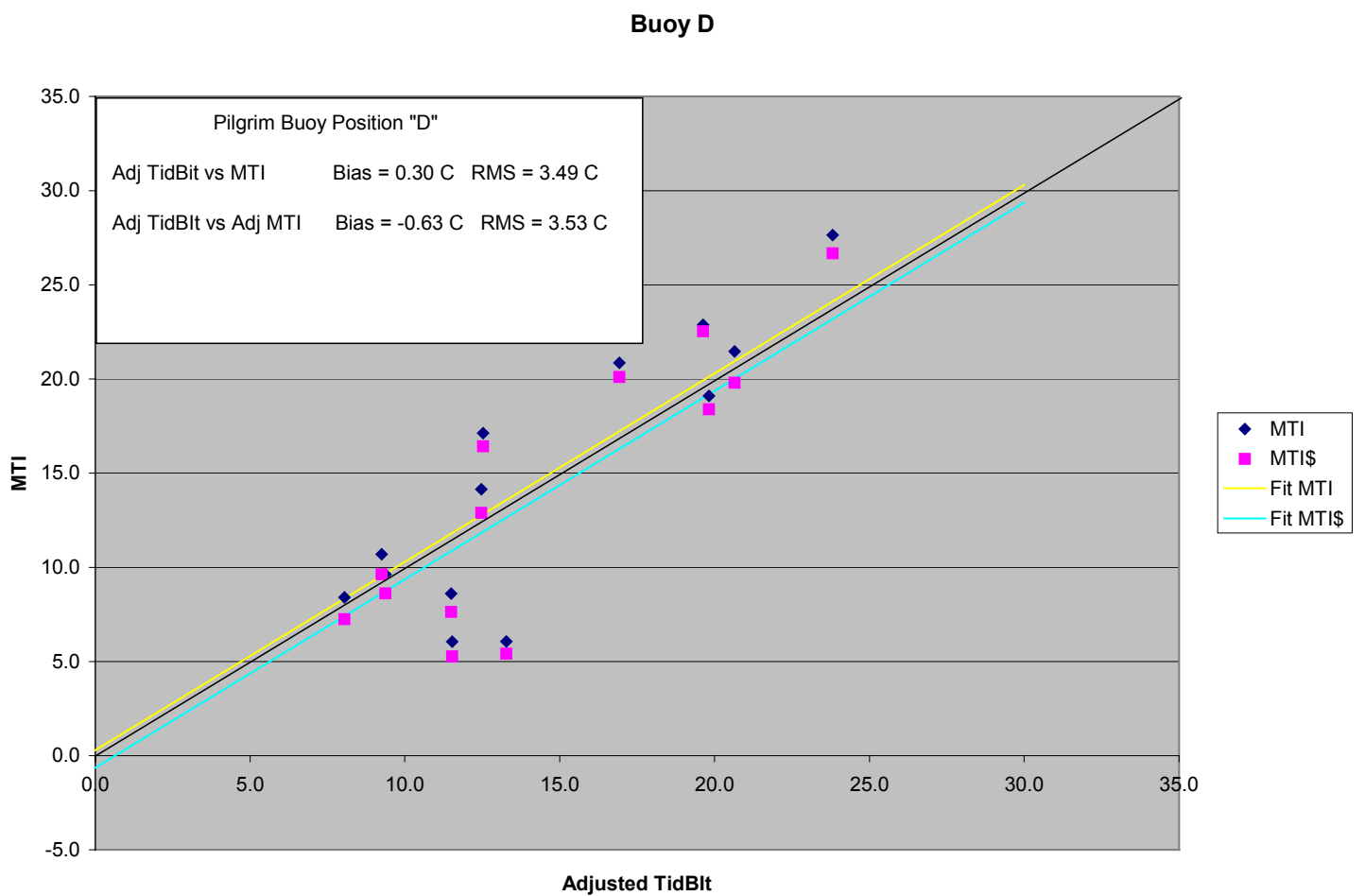

Figure 8. Plot of WST-R and Adjusted TidBit Temperatures for Pilgrim Buoy Location "D". 


\section{Buoy $\mathrm{E}$}

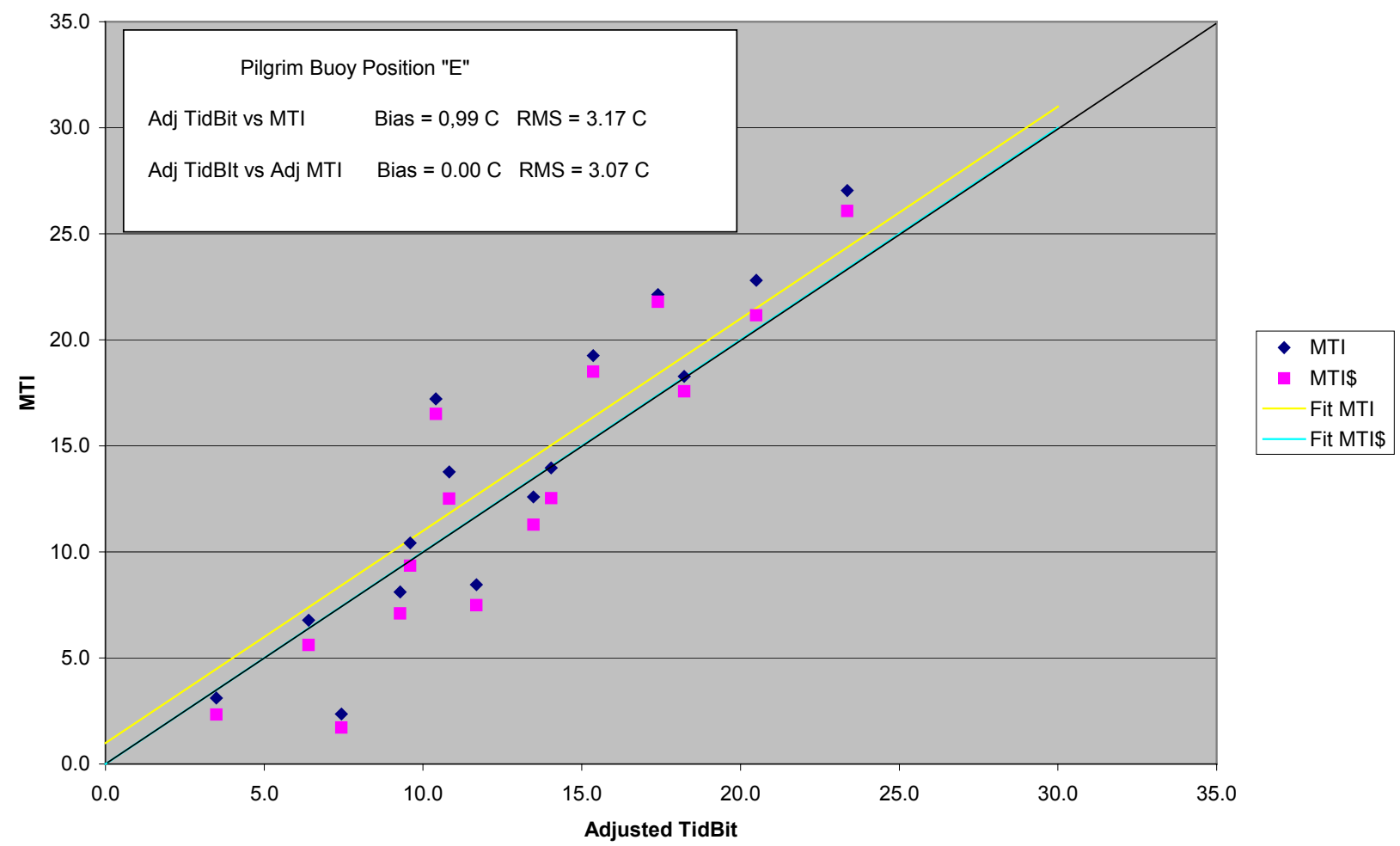

Figure 9. Plot of WST-R and Adjusted TidBit Temperatures for Pilgrim Buoy Location "E".

Buoy F

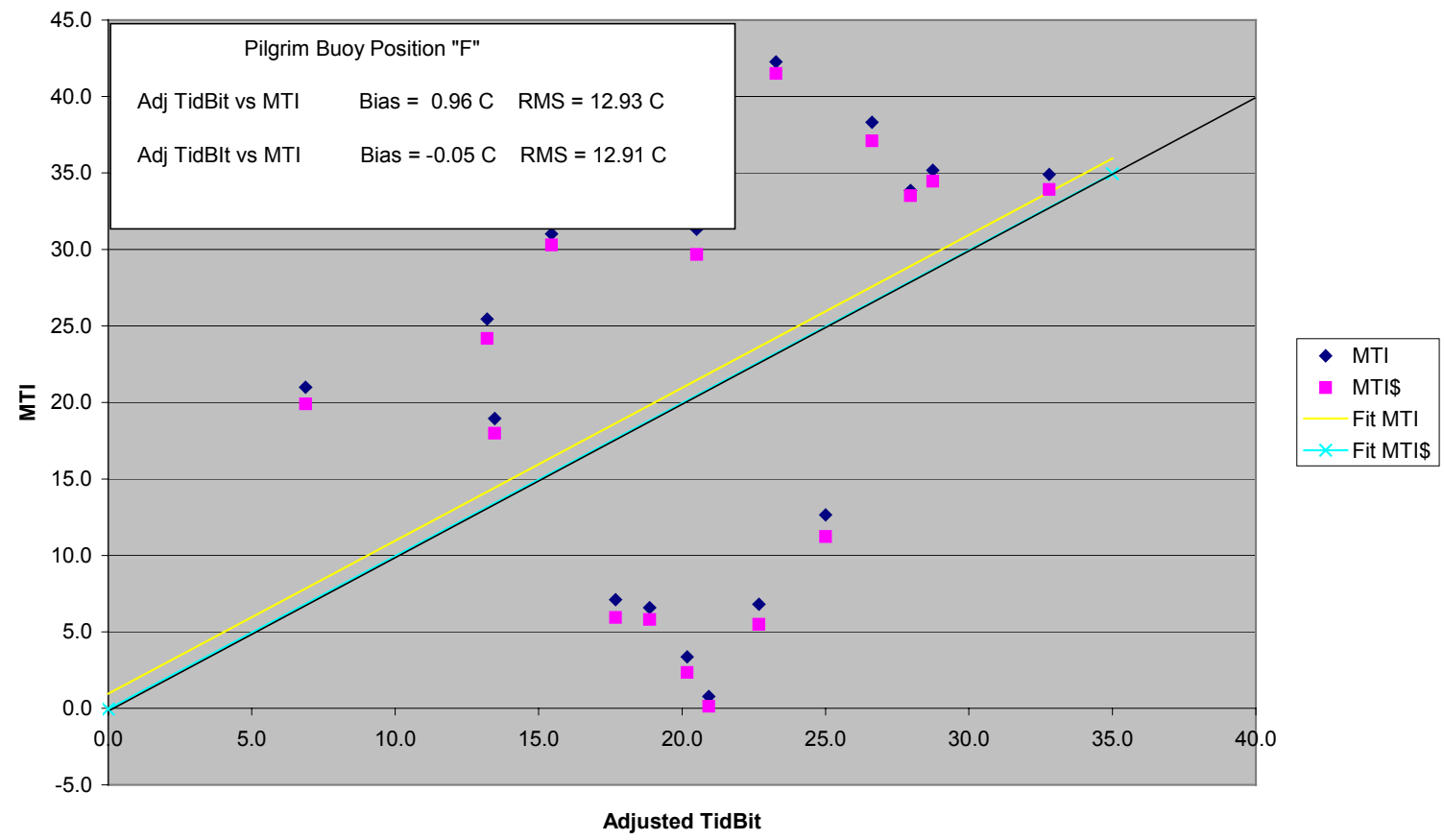

Figure 10. Plot of WST-R and Adjusted TidBit Temperatures for Pilgrim Buoy Location "F". 


\section{Water Temperature Retrieval Errors for Open Water Buoys}

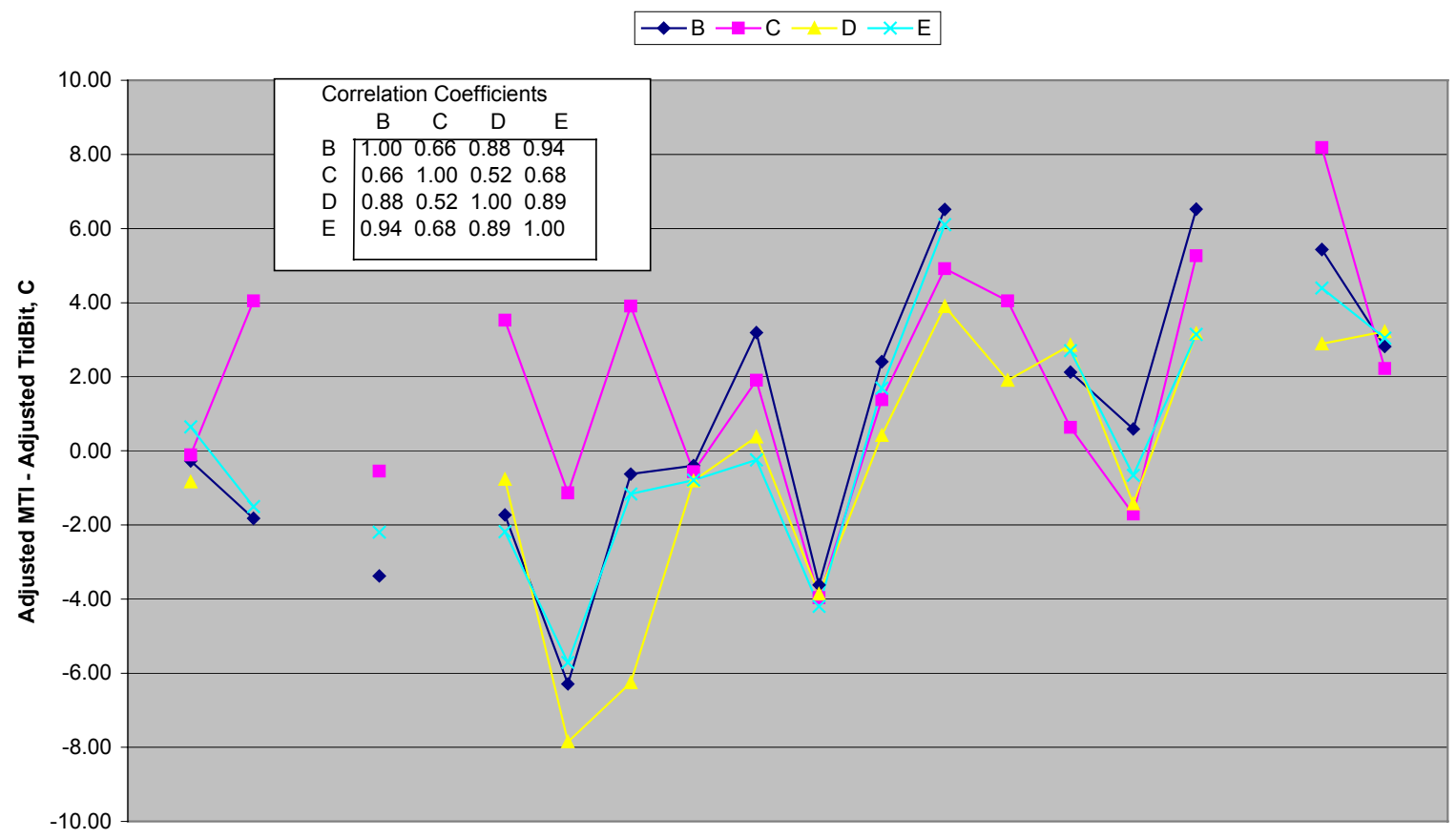

Figure 11. Water Temperature Retrieval Errors for all Open Buoys.

Average Water Temperatures for Open Water Buoys C, D and E

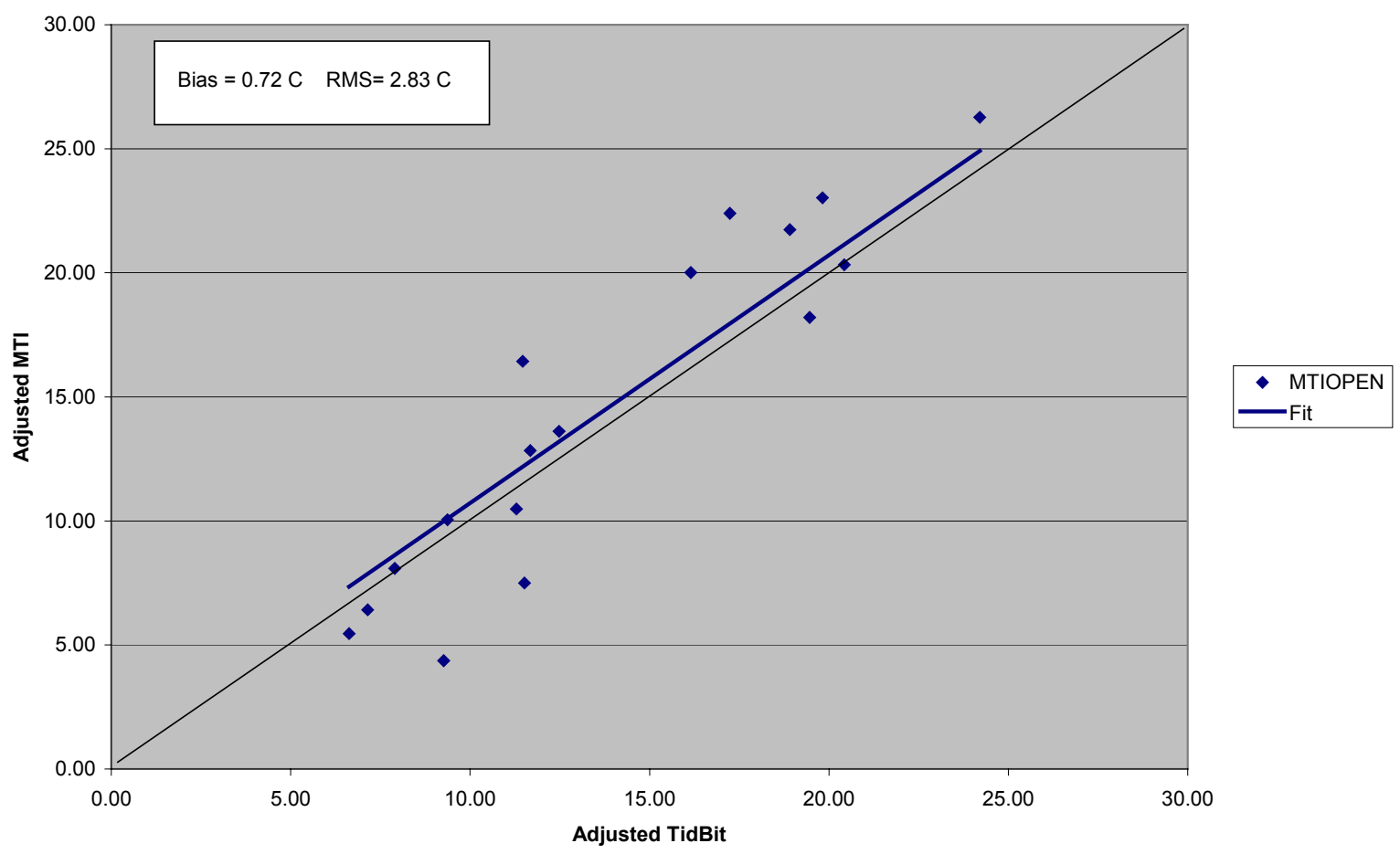

Figure 12. Water Temperature Retrievals for Combined Open Buoys C, D and E. 
WSRC-TR-2002-00380

\section{Tables}

Table 1. Coefficients for calculating WST from Top-of-Atmosphere brightness temperatures of MTI thermal bands for Zenith-to-MTI angles ranging from 0 to 40 degrees. (provided by William B. Clodius, LANL $1 / 28 / 02$ )

\begin{tabular}{|c|c|c|c|c|c|c|c|c|c|c|}
\hline Fit & Terms & D/N & Angle & SCA & Offset & J & K & L & M & N \\
\hline Lowtran & KLMN & $\mathrm{D}$ & 0 & All & 5.743 & & 0.33212 & -3.14438 & 1.90504 & 1.87483 \\
\hline Lowtran & KLMN & $\mathrm{D}$ & 5 & All & 5.795 & & 0.33412 & -3.15406 & 1.91016 & 1.87715 \\
\hline Lowtran & KLMN & $\mathrm{D}$ & 10 & All & 5.939 & & 0.3399 & -3.18222 & 1.92495 & 1.88404 \\
\hline Lowtran & KLMN & $\mathrm{D}$ & 15 & All & 6.21 & & 0.40727 & -3.40041 & 2.0104 & 1.94887 \\
\hline Lowtran & KLMN & $\mathrm{D}$ & 20 & All & 6.609 & & 0.42151 & -3.46828 & 2.04266 & 1.96835 \\
\hline Lowtran & KLMN & $\mathrm{D}$ & 25 & All & 7.176 & & 0.44035 & -3.55667 & 2.07981 & 1.99808 \\
\hline Lowtran & KLMN & $\mathrm{D}$ & 30 & All & 7.937 & & 0.46456 & -3.66945 & 2.12558 & 2.03733 \\
\hline Lowtran & KLMN & $\mathrm{D}$ & 35 & All & 8.959 & & 0.49464 & -3.80867 & 2.17788 & 2.08942 \\
\hline Lowtran & KLMN & $\mathrm{D}$ & 40 & All & 10.307 & & 0.52892 & -3.96954 & 2.23235 & 2.15537 \\
\hline & & & & & & & & & & \\
\hline Lowtran & JKLMN & $\mathrm{N}$ & 0 & All & 14.843 & 1.96669 & 0.64702 & -1.52437 & -3.54234 & 3.37936 \\
\hline Lowtran & JKLMN & $\mathrm{N}$ & 5 & All & 14.935 & 1.97006 & 0.64843 & -1.52463 & -3.55321 & 3.3853 \\
\hline Lowtran & JKLMN & $\mathrm{N}$ & 10 & All & 15.214 & 1.98006 & 0.65252 & -1.52509 & -3.58573 & 3.40298 \\
\hline Lowtran & JKLMN & $\mathrm{N}$ & 15 & All & 15.131 & 2.01508 & 0.66721 & -1.54074 & -3.6149 & 3.39894 \\
\hline Lowtran & JKLMN & $\mathrm{N}$ & 20 & All & 15.82 & 2.03828 & 0.67662 & -1.54024 & -3.69419 & 3.44213 \\
\hline Lowtran & JKLMN & $\mathrm{N}$ & 25 & All & 16.763 & 2.06801 & 0.68817 & -1.53823 & -3.79702 & 3.49761 \\
\hline Lowtran & JKLMN & $\mathrm{N}$ & 30 & All & 17.987 & 2.10568 & 0.70295 & -1.53484 & -3.92863 & 3.56809 \\
\hline Lowtran & JKLMN & $\mathrm{N}$ & 35 & All & 19.572 & 2.15121 & 0.72076 & -1.52952 & -4.0911 & 3.65506 \\
\hline Lowtran & JKLMN & $\mathrm{N}$ & 40 & All & 21.543 & 2.20745 & 0.73866 & -1.51156 & -4.28701 & 3.75045 \\
\hline
\end{tabular}


Table 2. Spatial Errors of WST at Pilgrim Buoy Locations for all Image Times.

\begin{tabular}{|c|c|c|c|c|c|c|}
\hline \multicolumn{7}{|c|}{ Spatial Errors of Water Temperature within 3 by 3 pixels at Pilgrim Buoys } \\
\hline Image ID & $\mathbf{A}$ & B & C & D & $E$ & $F$ \\
\hline 26384 & 1.40 & 0.48 & 0.09 & 0.89 & 0.63 & 1.86 \\
\hline 100213 & 1.53 & 0.34 & 0.36 & 0.78 & 0.30 & 1.32 \\
\hline 100255 & 2.03 & 0.10 & 1.22 & 0.86 & 0.75 & 2.93 \\
\hline 100594 & 2.26 & 0.27 & 1.29 & 1.65 & 0.72 & 2.22 \\
\hline 101142 & 1.41 & 1.05 & 2.57 & 1.98 & 1.20 & 1.28 \\
\hline 101172 & 1.80 & 2.02 & 1.06 & 3.05 & 1.06 & 1.72 \\
\hline 101737 & 3.98 & 0.28 & 0.93 & 1.50 & 0.49 & 1.83 \\
\hline 102089 & 1.54 & 0.06 & \begin{tabular}{|l|}
0.29 \\
\end{tabular} & 0.51 & 0.58 & 2.32 \\
\hline 103880 & 2.66 & 0.84 & 1.08 & 1.06 & 0.10 & 1.50 \\
\hline 103890 & 2.88 & 0.62 & 0.09 & 0.11 & 0.08 & 2.08 \\
\hline 103900 & 1.39 & 0.30 & 0.21 & 0.37 & 0.11 & 1.85 \\
\hline 103919 & 2.79 & 1.58 & 0.23 & 0.14 & 0.39 & 0.95 \\
\hline 104965 & 1.89 & 0.39 & 0.51 & 0.73 & 0.17 & 2.50 \\
\hline 105281 & 2.36 & 0.78 & 0.64 & 0.30 & 0.25 & 1.32 \\
\hline 105296 & 0.81 & 0.65 & 0.39 & 0.94 & 0.32 & 0.49 \\
\hline 105312 & 0.95 & 0.45 & 0.34 & 0.47 & 0.18 & 0.65 \\
\hline 105328 & 0.79 & 0.43 & 0.30 & 0.33 & 0.16 & 0.73 \\
\hline 105344 & 0.87 & 0.39 & 0.30 & 0.34 & 0.10 & 0.70 \\
\hline Ave & 1.85 & 0.61 & \begin{tabular}{|l|}
0.66 \\
\end{tabular} & 0.89 & 0.42 & 1.57 \\
\hline StDev & 0.85 & 0.50 & 0.62 & 0.75 & 0.34 & 0.70 \\
\hline
\end{tabular}


Table 3. Errors Associated with Adjusting the TidBit Temperatures at Pilgrim Buoy Locations.

\begin{tabular}{|c|c|c|c|c|}
\hline \multicolumn{5}{|c|}{ Error Analysis for Adjusted TidBit Temperatures at Pilgrim } \\
\hline & Average & Max & Average & Max \\
\hline Type Error & Buoys A \& F & Buoys A \& F & Buoys B, C, D \& E & Buoys B, C, D \& E \\
\hline TidBit Accuracy & 0.20 & 0.20 & 0.20 & 0.20 \\
\hline Skin Temperature Adjustment & 0.10 & 0.10 & 0.10 & 0.10 \\
\hline Warm Layer Adjustment & 0.35 & 0.35 & 0.35 & 0.35 \\
\hline Spatial Error & 1.71 & 3.45 & 0.65 & 2.21 \\
\hline Total Error, deg C & 1.76 & 3.47 & 0.77 & 2.25 \\
\hline
\end{tabular}

(Note the Max spatial error is equal to the average of the maximum for each buoy.) 
Table 4. Listing of all data used in the WST-R evaluation for Pilgrim.

\begin{tabular}{|c|c|c|c|c|c|c|c|c|c|c|c|c|c|c|c|c|c|c|}
\hline Date & Seq\# & TIME & Image\# & SCA Bias & StdD Bias & $\mathrm{N}-\mathrm{K}$ & MTI-A & MTI-B & MTI-C & MTI-D & MTI-E & MTI-F & MTI A\$ & MTI B \$ & MTI C\$ & MTI D\$ & MTI E\$ & MTI F\$ \\
\hline $6 / 3 / 00$ & 179 & 1655 & 17864 & & & & & & & & & & & & & & & \\
\hline $6 / 4 / 00$ & 183 & 1703 & 17947 & & & & & & & & & & & & & & & \\
\hline $8 / 22 / 00$ & 451 & 1642 & 26384 & -1.66 & 0.19 & 9.70 & 26.82 & 22.49 & 21.68 & 21.47 & 22.81 & 31.33 & 25.16 & 20.83 & 20.02 & 19.81 & 21.15 & 29.67 \\
\hline $11 / 19 / 00$ & 1033 & 1624 & 100213 & $\begin{array}{l}-1.42 \\
\end{array}$ & 0.31 & 6.68 & 12.09 & 9.90 & 16.39 & $\overline{14.76}$ & 13.96 & 12.65 & 10.67 & 8.48 & 14.97 & 13.34 & 12.54 & 11.23 \\
\hline $11 / 21 / 00$ & & & & & & & 11.12 & 10.64 & 15.24 & 17.37 & 15.52 & 12.81 & 11.12 & 10.64 & 15.24 & 17.37 & 15.52 & 12.81 \\
\hline $12 / 3 / 00$ & 1105 & 1621 & 100594 & -1.32 & 0.55 & 5.48 & 5.20 & 5.82 & 9.88 & 12.94 & 12.60 & 6.81 & 3.88 & 4.50 & 8.56 & 11.62 & 11.28 & 5.49 \\
\hline $12 / 18 / 00$ & 1172 & 1621 & 100843 & & & & & & & & & & & & & & & \\
\hline $1 / 2 / 01$ & 1239 & 1619 & 101142 & -1.01 & 0.20 & 6.42 & 3.92 & 3.03 & 9.57 & 9.62 & 8.11 & 3.36 & 2.91 & 2.02 & 8.56 & 8.61 & 7.10 & 2.35 \\
\hline $1 / 3 / 01$ & 1247 & 1626 & 101172 & -0.64 & 0.37 & 4.54 & \begin{tabular}{|c|}
-1.26 \\
\end{tabular} & -1.30 & 6.59 & 6.06 & 2.36 & 0.77 & -1.90 & -1.94 & 5.95 & 5.42 & 1.72 & 0.13 \\
\hline $2 / 3 / 01$ & 1378 & 1620 & 101737 & -0.78 & 0.20 & 5.61 & 5.54 & 3.25 & 9.55 & 6.05 & 3.11 & 6.58 & 4.76 & 2.47 & 8.77 & 5.27 & 2.33 & 5.80 \\
\hline $2 / 19 / 01$ & 1443 & 1617 & 102089 & -1.17 & 0.17 & 5.19 & 3.41 & 3.00 & 7.59 & 8.41 & 6.78 & 7.11 & 2.24 & 1.83 & 6.42 & 7.24 & 5.61 & 5.94 \\
\hline $4 / 29 / 01$ & 1764 & 1558 & 103880 & $\begin{array}{l}-1.08 \\
\end{array}$ & 0.21 & 5.62 & 18.54 & 14.17 & 12.25 & 10.70 & 10.43 & 20.99 & 17.46 & 13.09 & 11.17 & 9.62 & 9.35 & 19.91 \\
\hline $4 / 30 / 01$ & 1767 & 1603 & 103890 & -0.97 & 0.46 & 5.15 & 14.27 & 9.03 & 8.36 & 8.60 & 8.46 & 18.95 & 13.30 & 8.06 & 7.39 & 7.63 & 7.49 & 17.98 \\
\hline $5 / 1 / 01$ & 1770 & 1608 & 103900 & -1.26 & 0.33 & 7.31 & 20.53 & 15.86 & 14.37 & 14.15 & 13.77 & 25.44 & 19.27 & 14.60 & 13.11 & 12.89 & 12.51 & 24.18 \\
\hline $5 / 2 / 01$ & 1777 & 1613 & 103919 & -0.71 & 0.54 & 5.27 & 29.25 & 19.47 & 17.10 & 17.13 & 17.22 & 31.01 & 28.54 & 18.76 & 16.39 & 16.42 & 16.51 & 30.30 \\
\hline $6 / 30 / 01$ & 2039 & 1551 & 104965 & -1.23 & 0.18 & 9.17 & 28.72 & 22.26 & 23.08 & 24.97 & 24.73 & 38.32 & 27.49 & 21.03 & 21.85 & 23.74 & 23.50 & 37.09 \\
\hline $7 / 21 / 01$ & 2148 & 1544 & 105281 & -0.97 & 0.17 & 6.72 & 25.68 & 22.01 & 27.03 & 27.64 & 27.04 & 34.90 & 24.71 & 21.04 & 26.06 & 26.67 & 26.07 & 33.93 \\
\hline $7 / 22 / 01$ & 2153 & 1548 & 105296 & -0.71 & 0.41 & 7.80 & 22.69 & 16.64 & 19.35 & 19.10 & 18.28 & 35.18 & 21.98 & 15.93 & 18.64 & 18.39 & 17.57 & 34.47 \\
\hline $7 / 23 / 01$ & 2160 & 1552 & 105312 & -0.76 & 0.16 & 7.46 & 28.43 & 19.51 & 22.19 & 20.86 & 19.26 & 42.27 & 27.67 & 18.75 & 21.43 & 20.10 & 18.50 & 41.51 \\
\hline $7 / 24 / 01$ & 2167 & 1556 & 105328 & & & 6.86 & 28.09 & 19.63 & 19.27 & 21.39 & 21.12 & 33.80 & & & & & & \\
\hline $7 / 25 / 01$ & 2174 & 1600 & 105344 & -0.35 & 0.49 & 7.01 & 23.47 & 19.83 & 23.23 & 22.87 & 22.14 & 33.86 & 23.12 & 19.48 & 22.88 & 22.52 & 21.79 & 33.51 \\
\hline $9 / 7 / 01$ & 2423 & 1548 & 106353 & & & & & 19.41 & 18.52 & 23.02 & 23.68 & & & 19.41 & 18.52 & 23.02 & 23.68 & \\
\hline $10 / 2 / 01$ & 2553 & 1544 & 106971 & & & & & & & & & & & & & & & \\
\hline
\end{tabular}


Table 4 (continued)

\begin{tabular}{|c|c|c|c|c|c|c|c|c|c|c|c|c|c|c|c|c|c|c|}
\hline Date & Seq\# & TIME & Image\# & Spd m/sec & Skin & WarmLay & $A\left({ }^{*} \mathrm{C}\right)$ & $B\left({ }^{*} \mathrm{C}\right)$ & C $\left({ }^{*} \mathrm{C}\right)$ & D $\left({ }^{*} \mathrm{C}\right)$ & $E\left({ }^{*} \mathrm{C}\right)$ & $F\left({ }^{*} \mathrm{C}\right)$ & A $\left({ }^{*} \mathbf{C}\right) \#$ & B $\left({ }^{*} \mathbf{C}\right) \#$ & C $\left({ }^{*} \mathrm{C}\right) \#$ & D $\left({ }^{*} \mathrm{C}\right) \#$ & $\mathrm{E}\left({ }^{\star} \mathrm{C}\right) \#$ & F $\left({ }^{*} \mathrm{C}\right) \#$ \\
\hline $6 / 3 / 00$ & 179 & 1655 & 17864 & 5.60 & 0.37 & $\begin{array}{l}0.07 \\
\end{array}$ & 15 & 14.7 & & 20.2 & 13.5 & 28.8 & 14.68 & 14.39 & & \begin{tabular}{|l|}
19.89 \\
\end{tabular} & 13.21 & 28.54 \\
\hline $6 / 4 / 00$ & 183 & 1703 & 17947 & 7.20 & \begin{tabular}{|l|}
0.33 \\
\end{tabular} & 0.02 & 14.8 & 16.4 & & 20.4 & 19.1 & 29.5 & 14.51 & 16.13 & & 20.05 & 18.76 & 29.21 \\
\hline $8 / 22 / 00$ & 451 & 1642 & 26384 & 2.37 & 0.46 & 1.08 & 20.3 & 20.5 & 19.5 & 20 & 19.9 & 19.9 & 20.88 & 21.10 & 20.13 & 20.65 & 20.50 & 20.51 \\
\hline $11 / 19 / 00$ & 1033 & 1624 & 0213 & .60 & 0.43 & .39 & 9.58 & 10.3 & 11 & & 14.1 & 25 & 9.54 & 10.30 & 10.92 & & 14.04 & 25.00 \\
\hline \multicolumn{19}{|l|}{$11 / 21 / 00$} \\
\hline $12 / 3 / 00$ & 1105 & 1621 & 00594 & 1.70 & 0.49 & 1.90 & 5.86 & 6.46 & 7.69 & & 12.1 & 21.3 & 7.28 & 7.88 & 9.11 & & 13.48 & 22.68 \\
\hline $12 / 18 / 00$ & 1172 & 1621 & 100843 & 4.20 & 0.41 & 0.23 & 5.39 & 5.37 & 12.1 & & 14.5 & 22.2 & 5.21 & 5.19 & 11.87 & & 14.36 & 22.01 \\
\hline $1 / 2 / 01$ & 1239 & 1619 & 101142 & 2.60 & 0.46 & 0.89 & 3.02 & 3.31 & 4.6 & 8.94 & 8.84 & 19.7 & 3.46 & 3.75 & 5.04 & 9.38 & 9.28 & 20.18 \\
\hline $1 / 3 / 01$ & 1247 & 1626 & 101172 & 1.30 & 0.50 & 2.66 & 1.92 & 2.19 & 4.92 & 11.1 & 5.27 & 18.8 & 4.08 & 4.35 & 7.08 & 13.27 & 7.43 & 20.93 \\
\hline $2 / 3 / 01$ & 1378 & 1620 & 101737 & 3.20 & 0.44 & 0.54 & 2.71 & 2.99 & 4.76 & 11.4 & 3.39 & 18.8 & 2.81 & 3.09 & 4.86 & 11.52 & 3.49 & 18.87 \\
\hline $2 / 19 / 01$ & 1443 & 1617 & 102089 & 5.20 & 0.38 & 0.10 & 2.55 & 2.51 & 7.26 & 8.33 & 6.68 & 18 & 2.27 & 2.23 & 6.98 & 8.05 & 6.40 & 17.68 \\
\hline 4/29/01 & 1764 & 1558 & 103880 & 3.04 & 0.44 & 0.62 & 9.58 & 9.72 & 9.09 & 9.07 & 9.42 & 6.7 & 9.75 & 9.89 & 9.26 & 9.24 & 9.59 & 6.87 \\
\hline 4/30/01 & 1767 & 1603 & 103890 & 1.19 & 0.50 & 2.93 & 8.8 & 9.25 & 8.93 & 9.07 & 9.26 & 11 & 11.23 & 11.68 & 11.36 & 11.50 & 11.69 & 13.47 \\
\hline $5 / 1 / 01$ & 1770 & 1608 & 103900 & 3.09 & 0.44 & 0.59 & 11.6 & 12 & 11.6 & 12.3 & 10.7 & 13.1 & 11.74 & 12.19 & 11.73 & 12.47 & 10.82 & 13.21 \\
\hline $5 / 2 / 01$ & 1777 & 1613 & 103919 & 3.35 & 0.43 & 0.48 & 11.3 & 12.2 & 11.4 & 12.5 & 10.4 & 15.4 & 11.32 & 12.24 & 11.47 & 12.52 & 10.40 & 15.45 \\
\hline 6/30/01 & 2039 & 1551 & 104965 & 3.81 & 0.42 & 0.32 & 17.5 & & 17.9 & 21.9 & & 26.7 & 17.42 & & 17.80 & 21.83 & & 26.62 \\
\hline $7 / 21 / 01$ & 2148 & 1544 & 105281 & 2.10 & 0.47 & 1.36 & 17.8 & 18 & 24.5 & 22.9 & 22.5 & 31.9 & 18.72 & 18.92 & 25.43 & 23.82 & 23.37 & 32.80 \\
\hline $7 / 22 / 01$ & 2153 & 1548 & 105296 & 4.02 & 0.41 & 0.27 & 14.8 & 15.5 & 20.5 & 20 & 18.4 & 28.9 & 14.68 & 15.34 & 20.35 & 19.82 & 18.23 & 28.74 \\
\hline 7/23/01 & 2160 & 1552 & 105312 & 3.97 & 0.42 & 0.28 & 11.9 & 12.4 & 16.3 & 17.1 & 15.5 & 23.4 & 11.75 & 12.23 & 16.17 & 16.93 & 15.36 & 23.27 \\
\hline $7 / 24 / 01$ & 2167 & 1556 & 105328 & 4.69 & 0.40 & 0.15 & 11.9 & 13.9 & 15.5 & 18.2 & 14.7 & 26.5 & 11.64 & 13.67 & 15.27 & 17.93 & 14.47 & 26.30 \\
\hline $7 / 25 / 01$ & 2174 & 1600 & 105344 & 3.51 & \begin{tabular}{|l|}
0.43 \\
\end{tabular} & 0.42 & 13.3 & 14.1 & 14.7 & 19.6 & 17.4 & 28 & 13.26 & 14.05 & 14.70 & 19.63 & 17.40 & 27.96 \\
\hline 9/7/01 & 2423 & 1548 & 106353 & 2.78 & 0.45 & 0.77 & 15.3 & 16.3 & 16 & 19.5 & 20.3 & 30 & 15.62 & 16.60 & 16.30 & 19.80 & 20.64 & 30.32 \\
\hline
\end{tabular}


WSRC-TR-2002-00380

Table 5. Listing and definitins of all column headings on Table 4.

\begin{tabular}{|c|c|}
\hline Heading & Definition \\
\hline Date & Date GMT \\
\hline Seq\# & MTI Image Sequence Number \\
\hline TIME & Time GMT \\
\hline Image\# & MTI Image Number \\
\hline SCA Bias & SCA center - SCA east \\
\hline StdD Bias & Standard Deviation off SCA Bias \\
\hline $\mathbf{N}-\mathbf{K}$ & Brightness Temperature MTI band N - Brightness Temperature MTI band $\mathrm{K}$ \\
\hline MTI-A & Robust Temperature Retrival at Pilgrim Buoy Location A \\
\hline MTI-B & Robust Temperature Retrival at Pilgrim Buoy Location B \\
\hline MTI-C & Robust Temperature Retrival at Pilgrim Buoy Location C \\
\hline MTI-D & Robust Temperature Retrival at Pilgrim Buoy Location D \\
\hline MTI-E & Robust Temperature Retrival at Pilgrim Buoy Location E \\
\hline MTI-F & Robust Temperature Retrival at Pilgrim Buoy Location A \\
\hline MTI A\$ & SCA Adjusted Robust Temperature Retrival at Pilgrim Buoy Location A \\
\hline MTI B\$ & SCA Adjusted Robust Temperature Retrival at Pilgrim Buoy Location B \\
\hline MTI C\$ & SCA Adjusted Robust Temperature Retrival at Pilgrim Buoy Location C \\
\hline MTI D\$ & SCA Adjusted Robust Temperature Retrival at Pilgrim Buoy Location D \\
\hline MTI E\$ & SCA Adjusted Robust Temperature Retrival at Pilgrim Buoy Location E \\
\hline MTI F\$ & SCA Adjusted Robust Temperature Retrival at Pilgrim Buoy Location F \\
\hline Spd NMC & Surface wind speed, $\mathrm{m} / \mathrm{sec}$, from nearest airport and/or Pilgrim Met Tower \\
\hline Skin & Skin Temperature Adjustment $=-0.546^{\star} \exp \left(-0.0696^{*}\right.$ Spd $)$ \\
\hline WarmLay & Warm Layer Adjustment at $30 \mathrm{~cm}$ depth $=+7.92^{*} \exp \left(-0.839^{*} \mathrm{Spd}\right)$ \\
\hline$A\left({ }^{*} \mathbf{C}\right)$ & TidBit Water Temperature at Pilgrim Buoy Location A \\
\hline $\mathrm{B}\left({ }^{*} \mathrm{C}\right)$ & TidBit Water Temperature at Pilgrim Buoy Location B \\
\hline $\mathbf{C}\left({ }^{*} \mathrm{C}\right)$ & TidBit Water Temperature at Pilgrim Buoy Location C \\
\hline$D\left({ }^{*} \mathrm{C}\right)$ & TidBit Water Temperature at Pilgrim Buoy Location D \\
\hline$E\left({ }^{*} C\right)$ & TidBit Water Temperature at Pilgrim Buoy Location E \\
\hline $\mathbf{F}\left({ }^{*} \mathbf{C}\right)$ & TidBit Water Temperature at Pilgrim Buoy Location F \\
\hline $\mathbf{A}\left({ }^{*} \mathrm{C}\right) \#$ & Skin-Temperature Adjusted TidBit Water Temperature at Pilgrim Buoy Location $\mathrm{A}$ \\
\hline $\mathrm{B}\left({ }^{*} \mathrm{C}\right) \#$ & Skin-Temperature Adjusted TidBit Water Temperature at Pilgrim Buoy Location B \\
\hline $\mathrm{C}\left({ }^{*} \mathrm{C}\right) \#$ & Skin-Temperature Adjusted TidBit Water Temperature at Pilgrim Buoy Location C \\
\hline $\mathrm{D}\left({ }^{*} \mathrm{C}\right) \#$ & Skin-Temperature Adjusted TidBit Water Temperature at Pilgrim Buoy Location D \\
\hline $\mathrm{E}\left({ }^{*} \mathrm{C}\right) \#$ & Skin-Temperature Adjusted TidBit Water Temperature at Pilgrim Buoy Location $\mathrm{E}$ \\
\hline $\mathbf{F}\left({ }^{*} \mathbf{C}\right) \#$ & Skin-Temperature Adjusted TidBit Water Temperature at Pilgrim Buoy Location F \\
\hline
\end{tabular}


Table 6. Summary of Bias and RMS error for WST-R and TidBit comparisons.

Summary of Bias and RMS Error between MTI water temperatures and Ground Truth at Six Pilgrim Buoy Locations. All values are in degrees $C$.

\begin{tabular}{|c|c|c|c|c|c|c|c|c|c|c|c|c|}
\hline & BIAS A & RMS A & BIAS B & RMS B & BIAS C & RMS C & BIAS D & RMS D & BIAS E & RMS E & BIAS F & RMS F \\
\hline TidBit vs MTI & 6.55 & 8.69 & 2.09 & 3.71 & 3.35 & 4.19 & 0.95 & 3.18 & 1.51 & 2.99 & 1.44 & 12.72 \\
\hline TidBit vs Adjusted MTI & 5.55 & 8.03 & 1.10 & 3.35 & 2.34 & 3.52 & 0.00 & 3.01 & 0.52 & 2.69 & 0.44 & 12.67 \\
\hline Adjusted TidBit vs MTI & 6.07 & 8.63 & 1.56 & 3.90 & 2.86 & 4.13 & 0.30 & 3.49 & 0.99 & 3.17 & 0.96 & 12.93 \\
\hline \multirow{2}{*}{$\begin{array}{l}\text { Adjusted TidBit vs Adjusted } \\
\text { MTI }\end{array}$} & 5.07 & 8.02 & 0.58 & 3.71 & 1.86 & 3.59 & -0.63 & 3.53 & 0.00 & 3.07 & -0.05 & 12.91 \\
\hline & BIAS & RMS & & & & & & & & & & \\
\hline $\begin{array}{l}\text { Average Open Water (B, C, D } \\
\text { and E) Unadjusted }\end{array}$ & 1.98 & 3.52 & & & & & & & & & & \\
\hline $\begin{array}{l}\text { Average Open Water (B, C, D } \\
\text { and E) Adjusted }\end{array}$ & 0.45 & 3.48 & & & & & & & & & & \\
\hline & & & & & & & & & & & & \\
\hline & & & & & & & & & & & & \\
\hline
\end{tabular}

